Referencia para citar este artículo: Acevedo-Tarazona, Á., \& Lagos-Cortés, E. (2019). Los estudiantes universitarios en la revolución cubana de 1959. Revista Latinoamericana de Ciencias Sociales, Niñez y Juventud, 17(1), 89-101. doi:https://dx.doi.org/10.11600/1692715x.17105

\title{
Los estudiantes universitarios en la revolución cubana de 1959*
}

\author{
Álvaro ACEVEDo-TARAZONA ** \\ Profesor Universidad Industrial de Santander, Colombia. \\ EMILIO LAGOS-CORTÉS ${ }^{* * * *}$ \\ Candidato a Magíster Universidad Industrial de Santander, Colombia.
}

\begin{abstract}
«Los estudiantes son los baluartes de la libertad y su ejército más firme.»

José Martí
\end{abstract}

\section{Artículo recibido en agosto 2 de 2018; artículo aceptado en octubre 24 de 2018 (Eds.)}

- Resumen (descriptivo): este artículo de reflexión aborda la actividad revolucionaria desarrollada por el movimiento estudiantil cubano de la Universidad de La Habana durante la lucha contra la dictadura de Fulgencio Batista entre los años de 1952 y 1959. A través del análisis de algunos documentos primarios se identifica el proceso de lucha entre los opositores conciliadores y los radicales ante la dictadura de Batista para obtener el apoyo del estudiantado cubano. Entre los radicales se ubicaron dos corrientes agrupadas en torno a Fidel Castro y José Antonio Echeverría; en la medida en que avanzó la lucha revolucionaria, la corriente propiamente estudiantil de Echeverría disminuyó su autonomía y terminó subordinándose política y militarmente a la dirección revolucionaria del Movimiento 26 de Julio.

Palabras clave: Cuba, dictadura, historia, movimiento estudiantil, revolución, violencia (Tesauro digital Unesco).

\section{University students in the Cuban Revolution of 1959}

- Summary (descriptive): This reflective article highlights the revolutionary activities carried out by the Cuban student movement at the University of Havana during the struggle against Fulgencio Batista's dictatorship between 1952 and 1959. Through the analysis of primary documents, the authors focus on the groups that were seeking to reconcile with the Batista dictatorship and radicals and their struggle to win the support of the Cuban student body. Among the radicals were two different factions linked to Fidel Castro and José Antonio Echeverría. As the revolutionary struggle increased, the group supporting Echeverría lost autonomy and ended up being politically and militarily incorporated into the revolutionary leadership of the July 26 Movement.

Key words: Cuba, dictatorship, history, student movement, revolution, violence (Unesco Digital Thesaurus).

\footnotetext{
* Este artículo corto se ocupa de las dinámicas en las que se desenvolvió el movimiento estudiantil universitario en Cuba durante la guerra contra la dictadura de Batista entre los años de 1956 y 1959. Hace parte del trabajo de investigación, Una crónica de 1968 en Colombia. Live fast, die young, que se desarrolla desde mayo de 2017 y que aún está en curso, de uno de los autores para obtener el título de Magíster en Historia en la Universidad Industrial de Santander. Esta investigación cuenta con financiación institucional de la Vicerrectoría de Investigación y Extensión de la Universidad Industrial de Santander. Código 2409. Área: Humanidades; subárea: Historia.

** Posdoctorado en Ciencias de la Educación, Universidad Pedagógica y Tecnológica de Colombia. Doctor en Historia, Universidad de Huelva. Profesor titular Universidad Industrial de Santander. Orcid: 0000-0002-3563-9213. Índice H5: 9. Correo electrónico: acetara@uis.edu.co

*** Abogado, Universidad Industrial de Santander. Candidato a Magíster en Historia, Universidad Industrial de Santander. Orcid: 0000-0001-65689388. Correo electrónico: emiliolagos79@hotmail.com
} 


\section{Os estudantes universitários na revolução cubana de 1959}

- Resumo (descritivo): este artigo de reflexão aborda a atividade revolucionária desenvolvida pelo movimento estudantil cubano da Universidade de Havana durante a luta contra a ditadura de Fulgencio Batista entre os anos de 1952 e 1959. Através da análise de alguns documentos primários, identificou-se o processo de luta entre os opositores conciliadores e os radicais frente a ditadura de Batista para obter o apoio do corpo discente cubano. Entre os radicais estavam duas correntes agrupadas em torno de Fidel Castro e José Antonio Echeverría; na medida em que a luta revolucionária avançou, o atual movimento estudantil de Echeverría diminuiu sua autonomia e acabou subordinando-se política e militarmente à liderança revolucionária do Movimento 26 de Julho.

Palavras-chave: Cuba, ditadura, história, movimento estudantil, revolução, violência (Unesco Digital Thesaurus).

-1. Introducción. -2. La Universidad de La Habana. -3. La respuesta estudiantil. -4. Conclusiones. -Lista de referencias.

\section{Introducción}

La Revolución Cubana fue uno de los acontecimientos sociales de mayor trascendencia ocurridos en América Latina en la segunda mitad del siglo pasado. Como resultado, la estructura de la sociedad cubana fue trasformada radicalmente. Su impacto también alcanzó la vida política del continente extendiendo la lucha guerrillera en muchos países y alineando a sus gobiernos con la política de Estados Unidos en contra de la revolución (Kalfon, 1997). Sus efectos se sintieron en otros continentes que atestiguaron la participación cubana en los procesos de liberación en Asia y África, y la conversión de la pequeña isla en protagonista de la política mundial, particularmente como líder del Movimiento de los Países No Alineados (Castañeda, 1995). Rojas refiere que:

La Revolución Cubana, como todas las revoluciones modernas, produjo un cambio radical en la sociedad y el Estado en la isla, y un giro notable en las relaciones de esa nación caribeña con el mundo (...) sin esa nación y sin sus líderes, sin sus políticas domésticas e internacionales, el último medio siglo, en América Latina y el Caribe, habría sido distinto. (Rojas, 2015, p. 10)

Uno de los rasgos notables de la Revolución Cubana fue que sus protagonistas eran jóvenes, especialmente jóvenes universitarios, que lograron derrocar a un férreo poder político e iniciar un proceso de transformación social exhibiendo un cambio en los agentes históricos de la revolución (Portantiero, 1978). Lo anterior está en sintonía con el protagonismo político que la juventud adquirió durante el siglo XX (Hobsbawm, 1998). En armonía con ello, la revolución implementó la llamada Gran Reforma a la educación universitaria de 1962, que obedeció no solo a la lógica interna de la Revolución Cubana, sino que hunde sus raíces en las demandas formuladas por el movimiento reformista de Córdoba (Argentina) de 1918, que estableció un derrotero para la educación superior en la región, buscando la vinculación de la universidad con la sociedad, y la implementación de un sistema de enseñanza científico (Laurencio-Leyva \& García-Hernández, 2018).

Es evidente la importancia que la educación superior y la Universidad han tenido en la conformación de la sociedad cubana y en el desarrollo de su historia nacional. Guadarrama (2005) señala la capital importancia que para la historia cubana ha tenido la Universidad de La Habana, claustro del que salieron sus principales figuras políticas y de la cultura, y que ha tenido una participación decisiva en momentos de crisis política en el país. También es notoria la participación que la Iglesia católica tuvo en la educación de las élites cubanas en la etapa previa al triunfo revolucionario (Segrelles-Álvarez, 2018). 
Los estudiantes cubanos que se enfrentaron a la dictadura de Batista se organizaron principalmente en dos tendencias. Una de ellas se agrupó en torno a Fidel Castro, inicialmente en la Facultad de Derecho, y la otra en torno a la Federación Estudiantil Universitaria presidida por José Antonio Echeverría. La conducta del movimiento estudiantil transitó desde una oposición basada en declaraciones públicas contra la dictadura al momento de su instauración en 1952 hasta llegar a un paro universitario indefinido vinculado a la lucha guerrillera para obtener la victoria en 1959, pasando por etapas de enfrentamientos y luchas callejeras contra los cuerpos represivos del régimen que resultaron en la radicalización política del estudiantado universitario cubano (Harnecker, 1988).

Uno de los periodos de mayor intensidad del proceso revolucionario fue el de la lucha armada contra la dictadura, llevada a cabo entre 1956 y 1959. Mencía (1985) considera que la guerra contra la dictadura de Batista puede considerarse la primera etapa de la Revolución Cubana. Durante este periodo uno de los protagonistas principales fue un sector del movimiento estudiantil que optó por acudir a las armas y sumarse a la lucha contra la dictadura luego de transitar un camino de radicalización política.

La dirigencia de la revolución continuamente ha conferido un papel de primer orden al estudiantado cubano como partícipe en la guerra contra la dictadura y como depositario de las esperanzas hacia el futuro del país, así lo expresó de manera reiterada Fidel Castro:

[...] en esta juventud están puestas las esperanzas de la Revolución, en esta juventud están puestas las más legítimas esperanzas de nuestro pueblo, y en esta juventud están puestas también las más legítimas y las más humanas esperanzas de nosotros, los revolucionarios, de todos los revolucionarios [...] con la sangre de Mella y con la sangre de José Antonio Echeverría, y con la sangre de muchos como ellos se fue haciendo la historia de la patria. (Castro, 1996, p. 4)

La vida política de Cuba estuvo marcada por la participación de los estudiantes en su proceso revolucionario: en 1933 fueron un factor activo en la lucha que derrocó al dictador Gerardo Machado. Al producirse el golpe militar que llevó al poder a Batista, los estudiantes están entre los principales opositores a su régimen, y su derrocamiento contó con una importante participación estudiantil (Oroz, 2007).

La historia política de la isla de Cuba ha sido accidentada. Fue el último territorio en América en obtener su independencia del imperio de España luego de una cruenta guerra que terminó en 1898. El proceso tardío de independencia de Cuba implicó que los grupos dirigentes derivados de esta fueran influidos por un universo ideológico más complejo que el solo liberalismo reinante durante los inicios del siglo XIX y posteriormente, pues la isla alcanzó su independencia de España cuando ya se han dado los procesos de independencia de la mayor parte de los países de América Latina. Para fines del siglo XIX ya existía la teoría del socialismo, y entre los colaboradores de José Martí se encuentra Carlos Baliño, uno de los futuros fundadores del Partido Obrero Socialista; de manera que desde el inicio de la vida política republicana cubana, el socialismo tuvo cierta influencia en la isla (Portantiero, 1978). La independencia de Cuba fue frustrada por la ocupación del territorio por parte de Estados Unidos hasta 1902, cuando se estableció una república constitucional. Posteriormente la vida política se caracterizó por cierta inestabilidad en la que se alternaron gobiernos dictatoriales y democráticos. Adicionalmente, para mediados del siglo XIX existía una interacción muy cercana con la vida política de la región del Caribe y Centroamérica, plagadas de dictaduras, frente a las cuales el estudiantado cubano continuamente expresó su rechazo. Ilustrativo de ello es que en 1947 Fidel Castro participó de la expedición de Cayo Confites, que se proponía derrocar al dictador dominicano Rafael Leonidas Trujillo (Ramonet, 2006).

De esta manera, para la realización de este artículo de reflexión fue necesario recurrir a una revisión analítica de diferentes textos de autores como Fidel Castro y Ernesto Guevara, íconos revolucionarios de América Latina, así como algunos documentos emitidos por la Federación Estudiantil Universitaria que permiten observar el trasegar y el desempeño de los universitarios en los diferentes escenarios de lucha en Cuba. Esta información primaria se contrastó con algunos textos historiográficos de reciente 
publicación, como es el caso de los artículos de Pablo Guadarrama y los textos de Mario Mencía, quienes desde una óptica internalista ofrecen argumentos de debate sobre una temática que, aún, reviste importancia en América Latina.

El proceso de análisis de los documentos primarios y la historiografía permitieron identificar el proceso de lucha durante la dictadura de Fulgencio Batista y la vinculación del estudiantado cubano alrededor de las figuras de Fidel Castro y José Antonio Echeverría. La constitución del Movimiento 26 de Julio permite observar el proceso de avance de la lucha revolucionaria y su impacto entre el estudiantado. A partir de este análisis se llega a la conclusión de que para la época, el estudiantado cubano surge como un nuevo actor político, imagen que se replicará entre la juventud latinoamericana.

\section{La Universidad de La Habana}

La Universidad de La Habana fue fundada en el año de 1728. En sus orígenes fue controlada por la Iglesia católica y tenía facultades de Filosofía y Letras, Derecho, Teología y Medicina. Durante el siglo XX se abrieron nuevas carreras enfocadas en aspectos técnicos y científicos impulsadas por la necesidad de formar el tipo de profesional que demandaba la creciente industria azucarera y el desarrollo del capitalismo en el país (Guadarrama, 2005). A la universidad cubana de los años cincuenta ingresaban jóvenes sin ninguna formación política. El claustro universitario significaba para esos jóvenes un mundo nuevo, uno que se extendía más allá de la finca o la fábrica de su familia, en el que se relacionaban con la historia de su país, con las corrientes políticas del momento y con las problemáticas sociales de su nación. Para los jóvenes de mayor sensibilidad ante los problemas sociales resultaba un lugar propicio para actuar frente a ellos, más si se considera que allí existían fuerzas políticas que denunciaban estas problemáticas. Para esta época la universidad contaba con un acumulado histórico en el que destacaba la existencia de personajes icónicos como Julio Antonio Mella, principal impulsor de la Reforma Universitaria en Cuba, y Antonio Guiteras, destacado nacionalista y revolucionario (Taibo II, 2009).

La universidad de los años cincuenta fue para los jóvenes cubanos un espacio de formación política, un lugar de encuentro con nuevas ideologías y, para algunos, un lugar donde se hicieron revolucionarios, así lo expresa Fidel Castro:

Cuando llegué a la Universidad era analfabeto político [...] Y la Universidad de La Habana no era la universidad de los humildes; era la universidad de las capas medias de la población, era la universidad de los ricos del país. Aunque los muchachos jóvenes solían estar por encima de las ideas de su clase y muchos de ellos eran capaces de luchar, y así lucharon a lo largo de la historia de Cuba [...] Y si le digo que en esa universidad me hice revolucionario fue porque hice contacto con algunos libros. (Ramonet, 2006, p. 99)

Castro resalta que en la vida de la universidad se respiraba un ambiente impregnado de culto a los héroes patrios, entre los que dominaba la figura de José Martí de quien abundaban las publicaciones, estatuas, calles y otros lugares con su nombre.

En Cuba la generación de jóvenes que vivieron en los años cincuenta fue conocida como la Generación del Centenario, en relación con los cien años del nacimiento del héroe nacional José Martí, en 1853. Para los años cincuenta, durante cinco décadas de vida republicana, los políticos con una intencionalidad oportunista y demagógica como lo señala Moro (2004), crearon un culto en torno a la personalidad de Martí para manipular al pueblo; paradójicamente, el pensamiento martiano desbordó la intención de los políticos y generó en los jóvenes cubanos una fuerte filiación martiana de profundo contenido ético que posteriormente se volvió contra quienes quisieron usarlo como un simple instrumento de control de la población y se convirtió en baluarte ideológico de quienes defendían una profunda transformación de la sociedad cubana. La cita de Moro indica que el credo martiano se cultivaba en los cubanos desde la educación primaria: «En todas las escuelas el culto martiano se expresaba formalmente en su presencia en bustos, fotos, en la confección de laminarios, en dramatizaciones de sus obras, en dibujarlo, en el conocimiento de su biografía» (Moro, 2004, p. 
97).

Para 1952, aunque existían varias pequeñas universidades privadas, el principal elemento de la educación superior lo conformaba el sector público que estaba compuesto por tres universidades: la Universidad de La Habana ubicada en el occidente del país, la Universidad Central de las Villas en la ciudad de Santa Clara y la Universidad de Oriente situada en Santiago de Cuba. La población universitaria de estos tres centros de estudios se cifraba en diecisiete mil estudiantes. Aunque la lucha estudiantil contra la dictadura se desplegó en las tres universidades oficiales de la isla y en diversos colegios, su epicentro se ubicó claramente en la Universidad de La Habana, centro universitario dominante que albergaba el principal número de estudiantes del país. Harnecker (1988) afirma que para 1953 la Universidad de La Habana contaba con dieciséis mil estudiantes matriculados, en tanto que la Universidad de Oriente apenas alcanzaba los mil estudiantes. Aquella universidad también se destacaba por concentrar a la mayoría de los dirigentes estudiantiles radicalizados políticamente, siendo los principales Fidel Castro, José Antonio Echeverría, Fructuoso Rodríguez y Faure Chomón, entre otros. Solo escapa Frank País, uno de los más importantes dirigentes de la lucha en la clandestinidad quien fuera estudiante de la Universidad de Oriente.

La preponderancia de la Universidad de La Habana como centro opositor a la dictadura puede explicarse, en parte, por el hecho de que hasta bien intensificada la guerra de guerrillas desplegada por el Movimiento 26 de Julio encabezado por Fidel Castro, la dictadura respetó la autonomía universitaria y aunque reprimía violenta y despiadadamente la protesta y la movilización callejera de los estudiantes y sectores que los secundaban, en ningún momento las instalaciones físicas de la universidad fueron ocupadas por las fuerzas de seguridad del Estado, de manera que los opositores a la dictadura contaban con un lugar físico cuyas puertas no cruzaba el aparato represivo de la misma: la universidad escapaba a la realidad diaria del resto de la sociedad cubana que sentía directamente el accionar de la policía y los militares (Harnecker, 1988; Guadarrama, 2005).

En el escenario político de la primera mitad del siglo XX se destacó la figura de Fulgencio Batista, quien para 1933 era un sargento del ejército que participó del movimiento revolucionario que logró derrocar al gobierno de Gerardo Machado, cabeza de una dictadura altamente represiva y corrupta vinculada a los intereses norteamericanos. Derrocado Machado, se estableció la llamada Pentarquía, presidencia colegiada compuesta por cinco personas, que ocupó el poder transitoriamente y de la que Batista ejercía control en la sombra. Batista se convirtió en jefe de las fuerzas armadas y controlaba la vida política del país, llegando a ser elegido senador y presidente para el periodo 19401944 (Rojas, 2015).

Para 1952 las candidaturas de Carlos Hevia y Roberto Agramonte, enemigos de Batista, se disputaban el primer lugar. El ahora general Batista deseaba retornar a la presidencia, para lo cual creó el Partido de Acción Unitaria, PAU, agrupación minoritaria en el ambiente político cubano. Las encuestas ponían a Batista en un lejano tercer lugar, se afirma que la principal motivación del golpe de estado de 1952, antes de las elecciones, fue evitar que se eligiera a uno de ellos (Rojas, 2015). Por tanto, el golpe de estado de 1952 no fue dirigido tanto contra el presidente en ejercicio, Carlos Prío Socarrás, sino para evitar que el Partido Ortodoxo, connotado enemigo político de Batista, ganara las elecciones, como pronosticaban las encuestas (Lupiáñez-Reinlein, 1985).

El 10 de marzo de 1952 Batista tomó el poder sin necesidad de derramamiento de sangre (Guevara, 1969). Ese mismo día los estudiantes de la Universidad de La Habana sentaron la que será su posición ante la dictadura y se dirigen al palacio presidencial a solicitar armas para defender el régimen constitucional (Mencía, 2007). El golpe de estado fue recibido por parte de la sociedad sin gran oposición; los distintos partidos políticos y los sectores obreros no realizaron grandes actos, quedando en los estudiantes el papel de denuncia y oposición a la nueva dictadura, dentro de una muy limitada capacidad de acción:

Los estudiantes, como fuerza relativamente organizada, fueron los únicos en capacidad de ofrecer resistencia inmediata a los golpistas, en medio de la sorpresa. Pero, sin más apoyo 
ni recursos que su tradicional rebeldía, solo pudieron concretar su acción en continuas protestas, más efectistas que efectivas, en tanto que sus locales se preparaban para servir de sede a cuantos [...] planes de lucha antidictatorial comenzaran a delinearse poco después. (Mencía, 1986b, p. 2)

Similar opinión expresa Rojas, quien afirma que la sociedad civil cubana recibió el golpe de estado con mucha pasividad:

El foco de resistencia a la dictadura se concentró en la Universidad de La Habana. Los estudiantes organizaron juramentos y entierros simbólicos de la constitución del 40 y manifestaciones públicas en la escalinata y en los alrededores del recinto, que eran disueltas por la policía. (Rojas, 2015, p. 31)

La universidad se convirtió en casi el único lugar que manifestaba su rechazo a la dictadura, pues cierta inmunidad conferida por la autonomía le permitió convertirse en punto de encuentro de los opositores a la dictadura y en ella llevaban a cabo sus actividades conspiratorias. No se trataba solo de estudiantes; en sus terrenos se encontraban distintos tipos de opositores al gobierno, desde sindicalistas, algunos comunistas, miembros del Partido Ortodoxo y de otras organizaciones políticas que, en esa relativa seguridad, podían coordinar y poner en práctica planes antigubernamentales. En sus territorios se entrenó militarmente, incluido el manejo de armas, a mil doscientos miembros del futuro Movimiento 26 de Julio (Ramonet, 2006), eso para mencionar solo a la principal organización que luchaba contra la dictadura. Al interior de la Universidad de La Habana había otras organizaciones que competían por obtener las simpatías estudiantiles en su rechazo a la dictadura, destacándose entre ellas el Directorio Revolucionario, organización que agrupaba a los estudiantes que actuaban bajo el liderazgo de la Federación Estudiantil Universitaria en cabeza de José Antonio Echeverría.

\section{La respuesta estudiantil}

La respuesta estudiantil al golpe de estado puede ser descrita a partir de la periodización realizada por Harnecker (1988) quien señala cinco etapas en el periodo que va desde 1952 hasta 1959. La primera etapa va desde marzo hasta noviembre de 1952, con declaraciones y movilizaciones contra la dictadura, pero sin grandes enfrentamientos violentos; la segunda hasta julio de 1953, con un aumento de los enfrentamientos entre estudiantes y el aparato represivo de la dictadura; la tercera etapa, caracterizada por la radicalización del movimiento estudiantil producto del impacto ocasionado por el asalto al Cuartel Moncada, va hasta fines de 1955; la cuarta va hasta marzo de 1957, presentando el inicio de actividades de grupos armados organizados por estudiantes; y la quinta etapa va hasta el triunfo revolucionario en 1959, caracterizada por un paro universitario indefinido y la incorporación de parte del estudiantado a la guerra de guerrillas bajo la hegemonía del Movimiento 26 de Julio.

Entre las líneas de acción estudiantil se destacó la participación en actos públicos conmemorativos a los héroes nacionales, como la evocación de la muerte y natalicio de José Martí y de Antonio Maceo, o las relativas a los héroes del movimiento estudiantil como Julio Antonio Mella y Antonio Guiteras, figuras vinculadas a la vida estudiantil y política de Cuba que en su momento se enfrentaron a las dictaduras que gobernaban la isla en épocas diferentes (Federación Estudiantil Universitaria, 1975). Así mismo convirtieron en escenarios de agitación y movilización las fechas de muerte de los nuevos mártires que irán cayendo en la lucha contra Batista, en especial la muerte de Rubén Batista Rubio, primer caído entre los estudiantes en lucha contra la dictadura, herido por la policía en un enfrentamiento callejero y quien falleció el 13 de febrero de 1953 (Nodal, Rojas, \& Sosa, 2013). Estas fechas se utilizaron para realizar actos políticos de protesta contra la dictadura, los cuales muchas veces terminaron en enfrentamientos contra la policía y militares, dejando decenas de detenidos, heridos y muertos, lo que a su vez contribuyó a la radicalización del estudiantado.

Para ilustrar lo anterior resulta útil el evento que relata Mencía (2007): el 15 de enero de 1953 el busto de Julio Antonio Mella amaneció manchado con una especie de asfalto, de inmediato los 
estudiantes se volcaron a las calles para protestar contra el ultraje que se atribuyó a esbirros del régimen, una vez los estudiantes en las calles, se desataron enfrentamientos con la policía, lo que produjo varios heridos, entre ellos el mencionado Rubén Batista. Esta sería la constante durante este periodo: a cada provocación por parte del régimen, los estudiantes reaccionaban lanzándose a las calles a exigir la renuncia del dictador mientras la policía los atacaba con porras, gases lacrimógenos y armas de fuego.

Entre los instrumentos que los estudiantes cubanos usaron para responder al golpe de estado, ocupó un lugar importante la revista Alma Mater, publicación universitaria que fue fundada por Julio Antonio Mella en noviembre de 1923 como órgano de los estudiantes de la Universidad de La Habana. El uso de medios impresos no era extraño para los rebeldes cubanos, José Martí había fundado el periódico Patria para impulsar la revolución de 1895. La revista Alma Mater se había dejado de publicar en mayo de 1934, aunque se había convertido en un importante vehículo de expresión de los estudiantes cubanos. El 12 de abril de 1952, a un mes del golpe batistiano, aparece de nuevo Alma Mater, anunciándose como portavoz de los opositores a la dictadura, lo que dejaba claro en su primera editorial: «No podía dejar de oírse la clarinada rebelde de Alma Mater en esta coyuntura decisiva para los destinos de la patria» (Contrera, 1989, p. 76). Esta publicación apareció muy ocasionalmente durante la dictadura, alcanzando doce números desde 1952 hasta 1956. En sus páginas se denunciaron los excesos de la dictadura tales como corrupción, torturas y violaciones a los derechos humanos, al tiempo que alentó a la lucha frontal contra el régimen. En 1958 la represión que siguió al asalto al Palacio Presidencial obligó a muchos miembros del Directorio Revolucionario a marcharse al exilio, asentándose varios de ellos en Miami, lugar donde se montó un programa radial llamado Alma Mater. En esa misma ciudad se editó un periódico semanal de igual nombre, tanto el programa de radio como el periódico se ocupaban de la realidad cubana, difundían las noticias que transmitía Radio Rebelde, la emisora de radio de los guerrilleros y alentaban la lucha contra la dictadura (Contrera, 1989).

Como se observa, al inicio de la dictadura la respuesta estudiantil se limitó a declaraciones de protesta contra la ruptura del orden constitucional en un contexto de relativa tolerancia de parte de la dictadura frente a las actividades de los estudiantes. Posteriormente en la medida en que la protesta estudiantil aumentó su intensidad, la represión aumentó su nivel, lo que, a su vez, impulsó un proceso de radicalización estudiantil que terminó en una declaración de guerra hacia la dictadura.

El papel de orientador de la lucha estudiantil contra la dictadura fue desempeñado principalmente por la Federación Estudiantil Universitaria, FEU, organización gremial de los universitarios cubanos. Creada el 20 de diciembre de 1922 en el contexto de la lucha por la Reforma Universitaria, la Federación Estudiantil Universitaria libró una lucha entre dos líneas políticas diferentes. La primera buscó salidas conciliadoras con el régimen y rechazaba la oposición armada. La segunda fue la línea revolucionaria que, en cabeza de José Antonio Echeverría, primero luchó por imponerse al interior de la organización estudiantil, y después, orientó el proceso de radicalización del estudiantado y su lucha armada contra la dictadura.

Ser dirigente estudiantil representaba un vehículo de ascenso político, por esta razón existían dirigentes interesados en tramitar la crisis en términos de negociación con la dictadura, oponiéndose a medidas como la lucha armada o a cualquier desafío frontal a la misma, y buscaban frenar el ímpetu rebelde de los estudiantes canalizándolo por caminos de civismo, toda vez que negociando existía la posibilidad de obtener posiciones en la burocracia estatal. Incluso se acusó a algunos dirigentes de «tramitar» las manifestaciones de los estudiantes, es decir, acordar con la policía los recorridos y alcances de las mismas (Solar-Cabrales, 2014).

Desde el ambiente estrictamente estudiantil la principal figura fue José Antonio Echeverría, estudiante de Arquitectura de la Universidad de La Habana quien se destacaría por ser el más notable vocero público del sector universitario declarado expresamente opositor a la dictadura. Se convirtió en impulsor de una corriente antidictatorial en el interior de la Federación Estudiantil Universitaria, y en el principal organizador del Directorio Revolucionario, organización clandestina de los estudiantes que con armas en mano pasaron a enfrentar a la dictadura. 
A medida que resultaba claro que las movilizaciones estudiantiles y la protesta popular no eran suficientes para la restauración del régimen constitucional anterior al golpe de estado, el sector más politizado entre los universitarios, llegó a la conclusión de la necesidad de disponer de un aparato clandestino que resultara capaz de desarrollar una lucha armada para deponer la dictadura. Con esta intención se seleccionó entre los estudiantes a los más osados y se inició un proceso de obtención de armas y entrenamiento para el combate, creando el Directorio Revolucionario. Este tipo de organización no era nueva en Cuba, caracterizada por la participación de los estudiantes y el uso de la violencia en la política. El mismo nombre de directorio no era nuevo. Durante la lucha contra el dictador Gerardo Machado se creó en 1927 el primer Directorio Estudiantil Universitario, de vida efímera; en 1930 se constituye el llamado Directorio Estudiantil del 30 (Contrera, 1989). Este último fue protagonista de primera importancia durante la llamada Revolución del 33, un gobierno progresista que solo se mantuvo por espacio de tres meses, de manera que con la creación del Directorio Revolucionario, los estudiantes estaban acudiendo al uso de un método ya conocido.

Como se indicó, entre finales de 1955 y marzo de 1957 se desarrolló una lucha estudiantil que presentaba grandes manifestaciones y movilizaciones fuertemente reprimidas por parte del régimen. Para enfrentar la represión creciente, los estudiantes organizaron grupos armados que en ocasiones se enfrentaron a los policías y militares que atacaban las movilizaciones, y en otras ocasiones llevaron a cabo acciones armadas con el fin de liquidar a los funcionarios del régimen mayormente vinculados con la represión.

Producto de la creciente violencia de parte de la dictadura y la consecuente radicalización de parte del estudiantado, la Federación Estudiantil Universitaria, por medio del Directorio Revolucionario, desarrolló la llamada «riposta armada» consistente en el uso de pequeños grupos de estudiantes con armas que debían enfrentarse a la policía y militares cuando estos dispararan contra las protestas. Entre las acciones más notables realizadas en ejercicio de la «riposta armada» se cuenta la ejecución del coronel Antonio Blanco Rico, jefe de la inteligencia del ejército (Mencía, 2007). Junto a lo anterior se dio un proceso de integración de sectores obreros a las luchas dirigidas por los estudiantes y de apoyo de estos a las expresiones de lucha obrera como huelgas, paros y la conmemoración del primero de mayo.

A la par, Fidel Castro y sus seguidores crearon el Movimiento 26 de Julio, M-26, para enfrentarse a la dictadura. Reunieron y entrenaron una fuerza de mil doscientos hombres y mujeres. En el universo de grupos opositores era la organización más fuerte por su disciplina, número de hombres y entrenamiento (Ramonet, 2006). Castro relata la forma en que la universidad sirvió como espacio para organizar la fuerza del 26 de Julio:

En el Salón de los Mártires montó Pedrito su centro de entrenamiento. La autonomía universitaria era bastante fuerte y los estudiantes se movilizaban mucho. La Colina Universitaria tenía determinada impunidad hasta un momento, durante toda una primera etapa, y entonces allí es donde iban los que protestaban. (Ramonet, 2006, p. 114)

Existe cierto consenso en torno a que el actor principal en el proceso de politización y radicalización de sectores estudiantiles fue la acción política y militar del Movimiento 26 de Julio que capturó la atención de los cubanos después de su intento por tomar por asalto los cuarteles militares en las ciudades de Santiago y Bayamo en el oriente del país, hechos conocidos popularmente como el asalto al Cuartel Moncada. Castro desde antes del golpe de estado ya era una figura política en Cuba, conocido por sus denuncias contra la corrupción del gobierno, la miseria en la que vivían los cubanos y la intromisión de los intereses estadounidenses en la vida política.

E126 julio de 1953 se produjo el asalto a los cuarteles Moncada y Carlos Manuel de Céspedes. Esta acción fue llevada a cabo por un grupo de jóvenes comandados por Fidel Castro cuando se convencen de que de parte de las distintas fuerzas políticas cubanas que se declaraban en oposición a la dictadura no se haría nada para derrocarla (Mencía, 1985). Castro comenzó a reclutar y entrenar a sus hombres y mujeres principalmente entre los miembros de las juventudes del Partido Ortodoxo, al que Castro estaba vinculado desde hacía años. En la operación para el asalto al Moncada participaron ciento 
veinte hombres y mujeres, todos con uniforme y grado de sargento, buscando pasar desapercibidos entre los militares del cuartel, solo llevaban zapatos de civil para reconocerse entre ellos (Ramonet, 2006, p. 122).

Si bien Castro operaba desde la Universidad de La Habana y dentro de su grupo participaban muchos estudiantes de la misma, debe señalarse, como lo indica Mencía (1980) que quienes participaron del asalto al Moncada, en su mayoría eran jóvenes vinculados a un ala radicalizada del Partido Ortodoxo, procedentes principalmente de sectores populares, campesinos y trabajadores urbanos. En este punto resulta importante precisar que, si bien Castro tenía gran influencia en el movimiento estudiantil y gran parte de su labor clandestina la realizó sirviéndose de la Universidad de La Habana, a la que identificó como el principal escenario de oposición a la dictadura, la estructura clandestina que organizó solo contaba con una minoría estudiantil. Esto, según Solar-Cabrales (2014), se explica porque durante la estadía de Castro como estudiante universitario cultivó muchos enemigos que temían su influencia en el estudiantado; a su vez, Fidel también desconfiaba de las dirigencias estudiantiles en la universidad, consideraba que muchos de quienes se declaraban revolucionarios solo jugaban a la revolución sin comprometerse seriamente. Solo hasta que una nueva dirección estudiantil radicalizada lograra ocupar la jefatura de la federación estudiantil resultó posible una acción conjunta entre la gente de Fidel y los estudiantes como grupo.

Luego del fracaso del asalto al Moncada, Fidel Castro y veintiocho sobrevivientes más fueron condenados a penas de prisión que dos años después serán anuladas mediante una amnistía de la dictadura que consideraba que ya no representaban peligro (Mencía, 1986a). Los recién excarcelados se exilaron en México donde organizaron lo que denominaron una «invasión» de la isla por parte de ochenta y dos expedicionarios. Tanto el asalto al Moncada, como el tiempo transcurrido en prisión y su posterior actividad en el exilio posicionó a Fidel entre los estudiantes cubanos como la figura indiscutible de la oposición a la dictadura (Mencía, 1980), condición que fue reconocida también en muchos lugares de Cuba. Zoila Rodríguez relata así la situación en el oriente de la isla:

Desde finales del mes de octubre de 1955 Frank País decidió incorporar el ARN al Movimiento Revolucionario 26 de Julio, convencido del liderazgo indiscutible de Fidel Castro, quien desde México organizaba la guerra y se comprometía a traerla a Cuba en el año 1956 al pueblo cubano. (Rodríguez, 2016, p. 12)

Esto facilitará más adelante la casi completa cooptación del movimiento estudiantil que terminó subordinado al 26 de Julio durante la lucha guerrillera. Durante este tiempo muchas de las manifestaciones estudiantiles se realizaron en solidaridad con los presos políticos, incluyendo a los asaltantes del Moncada, exigiendo su liberación y denunciando torturas contra ellos.

El proceso que llevó a que José Antonio Echeverría coincidiera con las posiciones de Castro puede rastrearse en el siguiente periplo: el 24 de febrero de 1956 en la Universidad de La Habana se anunció la conformación del Directorio Revolucionario, en junio adelantó en Cuba una fuerte campaña de denuncia de la detención de los hombres y mujeres del 26 de Julio en México por parte de la policía de ese país y el 26 de julio presidió los actos de conmemoración del tercer aniversario del asalto al Moncada al tiempo que señaló la significación histórica de tales acontecimientos y denunció los crímenes de la dictadura (Mencía, 1976).

Echeverría, durante el proceso de radicalización del estudiantado cubano, fue asumiendo posiciones que coincidían con las de Castro. Así, mientras que en octubre de 1955, en clara alusión al inicio de la guerra de guerrillas que se preparaba, Castro anunciaba que para 1956 «seremos libres o seremos mártires», en enero de 1956 Echeverría declaraba «a la juventud cubana nos sorprende 1956 en dramático y turbulento proceso... no se me juzgue apasionado ni iluso; el año de 1956, será el de la total liberación de Cuba. Al decir esto, ni imito, ni declaro, tal vez coincida» (Nuiry, 2011, p. 4).

El desarrollo de los acontecimientos llevó a que las dos fuerzas más comprometidas en el combate a la dictadura, el Movimiento 26 de Julio y la Federación Estudiantil Universitaria, negociaran la unión de sus fuerzas para derrocar a Batista. Esta unión se selló en México el 29 de agosto de 1956, tres meses antes del desembarco del Granma, mediante la Carta de México, que definía como propósito de 
la unión el «derrotar a la tiranía batistiana y llevar a cabo la Revolución Cubana». La Carta de México tiene tal importancia que con base en ella se acordó que para la fecha del desembarco del Granma las dos organizaciones harían coincidir sus acciones militares con el fin de dispersar las fuerzas de la dictadura evitando que pudieran concentrarse contra los guerrilleros prestos a desembarcar. Honrando este compromiso, el Directorio Revolucionario realizó un frustrado asalto al palacio presidencial del dictador el 13 de marzo de 1957 (Acevedo-Tarazona, 2017, p. 459).

El 30 de noviembre de 1956 en Santiago de Cuba estallaron motines organizados por Frank País, dirigente del Movimiento 26 de Julio en el oriente cubano (Guevara, 1969). Aunque se había planeado hacer coincidir el desembarco de los expedicionarios del Granma con una serie de levantamientos en distintas ciudades de Cuba, lo anterior no resultó ya que el viaje del barco desde México duró el doble del tiempo planeado y los levantamientos en distintos lugares de Cuba no alcanzaron a ser organizados por el 26 de Julio y sus aliados, entre estos, el Directorio Revolucionario, que no pudo organizar los ataques que debía realizar en La Habana. El 2 de diciembre de este año Fidel Castro junto a ochenta y dos copartidarios regresó a Cuba a bordo del Yate Granma.

El 27 de noviembre de 1956, seis días antes del desembarco del Granma, el estudiantado se lanzó a una huelga que condujo al cierre de la Universidad de La Habana por tiempo indefinido, la que solo se abrirá de nuevo al triunfo de la revolución en 1959 (Mencía, 2007), de manera que desde el inicio hasta el fin de la guerra de guerrillas, estando la universidad cerrada, para los estudiantes disminuyeron los espacios para las acciones de masas y el trabajo armado se puso a la orden del día. Esto facilita comprender por qué el movimiento estudiantil revolucionario terminó siendo absorbido por el Movimiento 26 de Julio.

La lucha guerrillera no comenzó nada bien. Los invasores fueron descubiertos al desembarcar, muriendo la mayoría de ellos; catorce sobrevivientes lograrán llegar hasta la Sierra Maestra e iniciarán la consolidación de una pequeña guerrilla. El 17 de enero de 1957 se produjo el primer combate victorioso para los guerrilleros en La Plata, en adelante el balance general se tornó favorable para Castro y sus hombres y mujeres, quienes cada día sumaban apoyos en campos y ciudades (Guevara, 1969), seduciendo a amplios sectores de la población, entre ellos al estudiantado que vio en los guerrilleros a los más decididos combatientes contra la dictadura.

La importancia de las acciones del Moncada y el desembarco del Granma respecto al movimiento estudiantil cubano radica en que captaron la atención de sectores juveniles cada vez más numerosos que seguían su propia ruta de radicalización. El enfrentar abiertamente la dictadura mediante la lucha armada ponía al Movimiento 26 de Julio y a Castro, como los principales protagonistas de la lucha contra la dictadura dotándolos de un formidable prestigio que atrajo a los estudiantes.

El 13 de marzo de 1957 Echeverría dirigió la operación militar del Directorio Revolucionario para tomar por asalto el Palacio Presidencial de Batista (Federación Estudiantil Universitaria, 1974). También tomaron la emisora Radio Reloj para anunciar la muerte del dictador y difundir un llamamiento al pueblo cubano para que se alzase contra la dictadura (Chomón, 2007). Fracasado el intento de ejecutar al dictador, los atacantes se retiraron y Echeverría murió combatiendo contra la policía. Ese mismo día Echeverría había redactado un documento que se conoció como su testamento político. En él reiteró su disposición a asumir las consecuencias que implicaba el luchar contra el régimen, señalando que cumplía con las obligaciones contraídas al firmar la Carta de México, convocaba al pueblo cubano a la resistencia cívica contra la dictadura, a abstenerse de apoyarla de cualquier manera, y en cambio, apoyar a quienes se habían volcado a las armas para combatirla, vinculó la lucha contra la dictadura a las luchas del héroe nacional José Martí por la libertad de la patria y definió a los estudiantes como la vanguardia de la lucha de ese momento (Nuiry, 1965).

De manera que los estudiantes universitarios desempeñaron un papel de primer orden durante la toma del poder por parte de los revolucionarios cubanos. En sintonía con ello, la educación superior recibió un tratamiento prioritario por parte de la revolución desde su llegada al poder: en 1962 se estableció la política de universalización de la educación superior que llevó a implementar un sistema que brinda a todo cubano la posibilidad de matricularse en cualquier programa de pregrado 
mediante la gratuidad del sistema y la cobertura del mismo en cada uno de los municipios del país (Santos-Gutiérrez \& López-Segrera, 2008). Como resultado, la revolución estableció un modelo socioeconómico que garantizó a la población cubana el acceso a políticas estatales marcadas por «...fórmulas de desarrollo sociopolítico para garantizar empleo, salud, erradicación del hambre y la pobreza, educación y previsión social con oportunidad de acceso universal y con un alto grado de cohesión y de solidaridad interna y hacia el mundo» (Fernández-Ríos, 2016).

La trascendencia que el liderazgo de la revolución reconoció a los universitarios se extendió fuera de las fronteras de la isla. Luego de tomarse el poder, en 1959 se realizaron giras que recorrieron varios países latinoamericanos; estas llevaron a que dirigentes cubanos se entrevistaran con líderes estudiantiles de países como México, Colombia, Panamá, Chile, Argentina y Venezuela (GarcíaTerrés, 1959). Esta cercanía con los universitarios latinoamericanos se comenzó a forjar incluso antes del triunfo revolucionario. Durante la lucha guerrillera, delegaciones del movimiento insurgente recorrieron el continente en busca de solidaridad política y apoyo económico para la guerra que se libraba contra la dictadura. Entre los países visitados por estas delegaciones se encuentra Argentina, cuya Universidad de Buenos Aires recibió a José Antonio Echeverría, presidente de la Federación Estudiantil Universitaria de Cuba, y jefe guerrillero, (Califa, 2013). Ricardo Lara, guerrillero colombiano, da cuenta de que en 1958 delegaciones de cubanos recorrieron colegios y universidades de Colombia en busca de la solidaridad de los estudiantes colombianos hacia la lucha guerrillera en Cuba (Castaño-Hernández, 1984). En Venezuela también se desplegó la solidaridad de los universitarios: durante 1958 se desarrolló la campaña «un bolívar para la Sierra», de la que se afirma reunió un millón en fondos para la guerrilla castrista (Ocando, 2008).

Todo lo expuesto confluyó hacía la decisión política por parte de un sector cada vez más amplio del movimiento estudiantil para enfrentarse mediante las armas de manera abierta a la dictadura, aspecto que llevó a que tal movimiento fuera prácticamente absorbido por el Movimiento Revolucionario 26 de Julio que desempeñó el papel de vanguardia en la lucha contra la dictadura, en especial, después de la muerte de Echeverría, el principal dirigente estudiantil de la Federación Estudiantil Universitaria y su Directorio Revolucionario.

\section{Conclusiones}

La juventud cubana de mediados del siglo XX apareció como nuevo actor de los procesos políticos de su país. Tal irrupción política de la juventud estuvo marcada en buena medida por su ingreso masivo a la universidad, espacio que les mostró un mundo cuyos horizontes iban más allá de las fincas y fábricas de sus padres; en las universidades los jóvenes se encontraron con filosofías y movimientos políticos que cuestionaban la realidad cubana y proponían programas para su transformación. En este ambiente no pocos jóvenes encontraron proyectos en los que pudieron expresar su rebeldía ante realidades que consideraban injustas; ese sentimiento de rebeldía en los jóvenes fue estimulado por la escuela cubana que durante décadas había desarrollado una campaña de propaganda en torno al héroe de la independencia José Martí y su ideario político, el que después se convirtió en estandarte de los jóvenes estudiantes universitarios rebeldes.

En contraste con la forma tímida en que reaccionaron distintos sectores de la sociedad cubana ante el golpe de estado de 1952, los estudiantes de sus universidades y de algunos colegios, de inmediato expresaron su rechazo y denunciaron la dictadura como un golpe criminal contra el régimen constitucional, presentándose un predominio de la Universidad de La Habana sobre el movimiento de lucha contra la dictadura, predominio que se explica por la gran influencia histórica que esta universidad ha ejercido en la vida política de la isla debido a su antigüedad y a su tamaño gigantesco en comparación con otras universidades de Cuba. Además, una tradición de respeto a la autonomía de la Universidad de La Habana, traducida en el no ingreso de la policía a sus terrenos, permitió un amplio margen de maniobra política a los estudiantes y a otros sectores que pudieron reunirse allí y organizar diversas formas de denuncia y combate contra la dictadura. 
Durante la existencia de la dictadura, dentro del movimiento estudiantil cubano operó un proceso de lucha interna entre dos tendencias: una revolucionaria que se oponía abiertamente a la dictadura y se radicalizaba progresivamente a favor de la lucha armada, y una tendencia conciliadora que buscaba la negociación política como forma de solucionar la crisis. En la medida en que la violencia se intensificó, el sector radical logró imponerse sobre el conciliador y obtuvo el apoyo amplio de sectores de la masa estudiantil que se lanzaron a la lucha armada para derrocar la dictadura. Se trató de un movimiento estudiantil que desde el inicio de la dictadura desempeñó un papel de primer orden en la oposición al régimen, y que en la medida en que la violencia se intensificó, fue siendo opacado y absorbido por el Movimiento 26 de Julio, la fuerza política dominante en el proceso revolucionario.

La Revolución Cubana fue el detonante de una juventud inconforme con su realidad, que vio en esta propuesta, la única forma de realizar un cambio en la sociedad. La universidad latinoamericana se convirtió en un fortín de ideologías y la revolución realizada por Fidel Castro, el Che Guevara y Camilo Cienfuegos traspasó las fronteras de la isla con la teoría del foco (Acevedo-Tarazona, 2016, p. 360). Los estudiantes latinoamericanos dejaron los libros para tomar las armas y tratar de consolidar el sueño revolucionario en toda América Latina, un ejemplo de ello es la constitución del Ejército de Liberación Nacional en Colombia.

\section{Lista de referencias}

Acevedo-Tarazona, Á. (2016). Memorias de una época: el movimiento estudiantil en Colombia en los años sesenta y setenta del siglo XX. Bucaramanga: Universidad Industrial de Santander.

Acevedo-Tarazona, Á. (2017). 1968. Historia de un acontecimiento: utopía y revolución en la universidad colombiana. Bucaramanga: Universidad Industrial de Santander.

Califa, J. S. (2013). El temprano impacto de la Revolución Cubana en el movimiento estudiantil argentino. El caso de la Universidad de Buenos Aires, 1959-1962. Nuevo Mundo Mundos Nuevos. doi:10.4000/nuevomundo.64973

Recuperado de: http://journals.openedition.org/nuevomundo/64973.

Castañeda, J. (1995). La utopía desarmada. Barcelona: Ariel.

Castaño-Hernández, O. (1984). El guerrillero y el político. Bogotá, D. C.: Oveja Negra.

Castro, F. (1996). Discurso en el acto homenaje a los mártires del asalto al Palacio Presidencial, el 13 de marzo de 1962. La Habana: Versiones Taquigráficas del Consejo de Estado.

Contrera, N. (1989). Alma Mater, la revista de Mella. La Habana: Editorial de Ciencias Sociales.

Chomón, F. (2007). La hombrada de José Antonio. En E. Oltuski, H. Rodríguez, \& E. Torres-Cueva

(Ed.), Memorias de la revolución (pp. 194-206). La Habana: Imagen Contemporánea.

Federación Estudiantil Universitaria. (1974). Historia de una lucha. La Habana: FEU.

Federación Estudiantil Universitaria. (1975). Los estudiantes frente a las tiranías. La Habana: FEU.

Fernández-Ríos, O. (2016). La revolución cubana en un nuevo contexto histórico. Revista de Políticas

Públicas, (Número Especial), 51-62.

García-Terrés, J. (1959). Diario de un escritor en La Habana. Universidad de México, 13(7), 3-8.

Guadarrama, P. (2005). Etapas principales de la educación superior en Cuba. Rhela, (7), 49-72.

Guevara, E. (1969). Pasajes de la guerra revolucionaria. México, D. F.: ERA.

Harnecker, M. (1988). José Antonio Echeverría: el movimiento estudiantil en la Revolución Cubana.

La Habana: Taller Popular.

Hobsbawm, E. (1998). Historia del siglo XX. Buenos Aires: Crítica.

Kalfon, P. (1997). Che. Ernesto Guevara: una leyenda de nuestro tiempo. Barcelona: Plaza y Janes.

Laurencio-Leyva, A., \& García-Hernández, A. (2018). La reforma universitaria de 1962: un hito para

la educación superior cubana. Revista Cubana de Educación Superior, (1), 64-74.

Lupiáñez-Reinlein, J. (1985). El movimiento estudiantil en Santiago de Cuba 1952-1953. La Habana:

Editorial de Ciencias Sociales. 
Mencía, M. (1976). La Carta de México. La Habana: Bohemia.

Mencía, M. (1980). La prisión fecunda. La Habana: Editora Política.

Mencía, M. (1985). El grito del Moncada. Bohemia. Recuperado de: http://bohemia.cu/old/moncada60-aniversario/El\%20grito\%20del\%20Moncada/El-grito-del-moncada.html.

Mencía, M. (1986a). El grito del Moncada. La Habana: Editorial Política.

Mencía, M. (1986b). Tiempos precursores. La Habana: Editorial de Ciencias Sociales.

Mencía, M. (2007). El Directorio Revolucionario y la FEU de José Antonio Echeverría. En E. Oltuski, H. Rodríguez, \& E. Torres-Cueva (Ed.), Memorias de la revolución (pp. 166-193). La Habana: Imagen Contemporánea.

Moro, S. (2004). Nostalgias de una habanera del cerro. La Habana: La Memoria.

Nodal, M., Rojas, A., \& Sosa, I. M. (2013). Bosquejo histórico del desarrollo del movimiento estudiantil universitario en Cuba. Pedagogía Universitaria, XVIII(2), 15-25.

Nuiry, J. (1965). José Antonio a través de su testamento político. La Habana: Universidad de La Habana.

Nuiry, J. (2011). Cuando la unidad parió jóvenes invencibles. Juventud Rebelde. Recuperado de: http://www.juventudrebelde.cu/cuba/2011-08-29/cuando-la-unidad-pario-jovenes-invencibles.

Ocando, C. (2008). Revelan detalles de entrega secreta de armas a Castro. El Nuevo Herald. Recuperado de: https://www.elnuevoherald.com/noticias/article1931719.html.

Oroz, F. (2007). El movimiento estudiantil en la revolución cubana. Aportes ideológicos a la construcción de una nueva hegemonía. Recuperado de: https://fyl.academia.edu/FlorenciaOroz.

Portantiero, J. (1978). Estudiantes y política en América Latina: el proceso de la reforma universitaria (1918-1938). México, D. F.: Siglo XXI.

Ramonet, I. (2006). Fidel Castro, biografía a dos voces. Bogotá, D. C.: Debate.

Rodríguez, Z. (2016). Presencia de Frank País García en la lucha estudiantil de Guantánamo contra la dictadura de Fulgencio Batista. Santiago, (Especial), 5-19.

Rojas, R. (2015). Historia mínima de la Revolución Cubana. México, D. F.: El Colegio de México.

Santos-Gutiérrez, S. C., \& López-Segrera, F. (2008). Revolución cubana y educación superior. Avaliação, 13(2), 391-424.

Segrelles-Álvarez, C. (2018). La Revolución Cubana y la iglesia católica: historia de un desencuentro. GeoGraphos, 9(102), 1-47.

Solar-Cabrales, F. J. (2014). Entre el golpe y el asalto: la Universidad de La Habana antes del 26 de julio de 1953. Santiago, (133), 129-139.

Taibo II, P. (2009). Tony Guiteras: un hombre guapo. La Habana: Editorial de Ciencias Sociales. 